\title{
Effect of acclimatization on earthworm's (Eisenia andrei) potential on olive mille wastewaters detoxification
}

\author{
Barhoum Kharbouch ${ }^{1,2}$, Hicham Lakhtar ${ }^{2}$, Sandrine Amat $^{2}$, Sevastianos Roussos ${ }^{2}$, Nathalie Dupuy ${ }^{2}$, Abdelhamid El \\ Mousadik $^{3}$ \\ ${ }^{1}$ Laboratory of Microbial Biotechnology and Crop Protection, Ibn Zohr University, Faculty of Sciences, BP 8106 Cité Dakhla Agadir, Morocco. \\ ${ }^{2}$ Aix Marseille Univ, CNRS, IRD, Avignon Université, IMBE, UMR 7263, 13397 Marseille Cedex20, France. \\ ${ }^{3}$ Laboratory of biotechnology and valorization of natural resources, university of Ibn Zohr, faculty of sciences, BP 8106 Cité Dakhla Agadir, \\ Morocco.
}

Highlights:

- Environmental impact of OMWW

Acclimated earthworms and bioconversion potential of OMWW

The high OMW ratio cause high mortality rate of earthworm

Keywords: Olive pomace; Olive mille wastewaters; Vermicomposting; Eisenia andrei; Acclimatization; Total phenols

\section{Abstract}

A laboratory vermicomposting (two months duration) was conducted to evaluate the effect of earthworm acclimatization (epigeic-Eisenia andrei) for decomposition and detoxification of olive mille wastewaters. The Earthworm growth rate and phenols reduction were superior in the mixture with acclimated earthworms (21.83 $\pm 0.01 \mathrm{mg} \mathrm{worm}^{-1} \mathrm{day}^{-1}$ and $72 \%$ respectively), than mixture with unacclimated earthworms $\left(4.67 \pm 0.01 \mathrm{mg} \mathrm{worm}^{-1}\right.$ day $^{-1}$ and $41 \%$ respectively). The data reveals that acclimatization of earthworms is a promising alternative for OMWW detoxification and vermicomposting (using $E$. andrei) is a suitable technology for olive by-products conversion into value-added material.

\section{Introduction}

In Morocco, olive production was estimated at about 16 million tons of olive and 3 million tons of olive oil (Lakhtar and Roussos, 2016). The extraction of olive oil generates huge quantities of wastes that may have a great impact on land and water environments because of their high phytotoxicity. Therefore, there is a need for guidelines to manage these wastes through technologies that minimize their environmental impact and lead to a sustainable use of resources. Although various physical, chemical and microbiological methods of disposal of organic solid wastes are currently in use, these methods are time consuming and involve high costs. Therefore, there is a pressing need to find out cost-effective alternative method of shorter duration particularly suited to Moroccan conditions. In this regard, the viability of using vermicomposting technique with cost-effective to stabilize and manage the organic solid wastes. The subsequent application of vermicompost to soil demonstrates that they can be used as organic amendments to promote plant growth and regenerate degraded soils (Melgar et al,. 2009). The aim of the present study was to test the effect of acclimatization of earthworms to OMWW on their potential in vermicomposting at the laboratory scale, and to test earthworm's potential for OMWW detoxification after and before acclimatization as a means of recycling and treating olive by-product (OMWW and OP).

\section{Material and Methods}

Two groups of earthworms (with clitellum) belonging to the species Eisenia andrei (Bouché, 1972), the first groups of earthworms were acclimatized to OMWW absorbed on olive-pomace, horse manure and wheat straw. The second groups of earthworms were bred in the same mixture without OMWW. Mixture composed of olive-pomace $(60 \%$ D.W), horse manure (30\% D.W) and wheat straw (10\% D.W) were made. Olive mill wastewater (OMWW) was added to the mixture then pre-composted for one month. The vermicomposting study of olive oil by-products on a laboratory scale was carried out in 2.5 I plastic box (1 kg of the mixture) and inoculated with 5 adult earthworms (with clitellum). Two mixtures were prepared; the first one was inoculated with acclimated earthworms and the second one was inoculated with unacclimated earthworms. Each treatment was run in triplicate.

The earthworm growth and reproduction were measured in each mixture. On the basis of the obtained data about the biomass, other parameters of earthworm such as biomass increase rate $\left(\mathrm{mg} \mathrm{day}^{-1}\right)$ and maximum weight achieved were produced with the help of the recorded data for different mixtures. The homogenized samples of 
the substrate material were collected every teen day during two months from each mixture, and they were analyzed for total phenol.

\section{Results and Discussion}

\section{- Earthworm growth and reproduction}

The mean earthworm biomass in mixture with acclimated earthworms increased significantly. In fact, the maximum mean biomass (ANOVA, $F=11.05, P<0.05$ ) reached in this mixture was $3.58 \mathrm{~g} \pm 0.30$ after 50 days, after this a decrease in the biomass was observed to reach $3.44 \pm 0.24 \mathrm{~g}$. It has been suggested that decline of earthworms biomass at the end of the vermicomposting process was due to the conversion and depletion of substrate (Garg et al., 2006). However no acclimated earthworms present a decrease in average biomass after then days of laboratory vermicomposting. After then days a slight increase in the average biomass was recorded, to reach $2.45 \pm 0.13 \mathrm{~g}$ at the end.

The growth rate expressed in $\mathrm{mg}$ of biomass acquired per earthworm per day was considered as a very good indicator for comparing earthworm growth in different substrates (Edwards and Arancon, 2004). The maximum growth rate was achieved in mixture with acclimated earthworms $\left(21.83 \pm 0.01 \mathrm{mg} \mathrm{worm}^{-1} \mathrm{day}^{-1}\right)$ (Tab.1). However, the growth rate of no acclimated earthworms $\left(4.67 \pm 0.001 \mathrm{mg} \mathrm{worm}^{-1}\right.$ day $\left.^{-1}\right)$ was 4.7 lower than reported with acclimated earthworms. Ganesh et al., 2009 reported that raw materials with high phenols fraction and lignin concentration (such as OP and OMWW) are not well adequate for growth and development of most earthworms' species. In this study the difference in mass gain between earthworms can be attributed to the effect of the acclimation of earthworms. El Hajjouji et al., (2007) contributed the difference of earthworm's growth rate between mixtures to antimicrobial and toxic effect of OMWW, which inhibits microbial activity that is essential for organic matter degradation by earthworms.

Table 1: Earthworms biomass and growth rate during vermicomposting process (mean $\pm S D, n=3$ ).

\begin{tabular}{|c|c|c|c|c|c|}
\hline Mixture & $\begin{array}{l}\text { Mean initial } \\
\text { earthworm } \\
\text { biomass }(\mathrm{g})\end{array}$ & $\begin{array}{l}\text { Mean } \\
\text { maximum } \\
\text { biomass } \\
\text { achieved (g) }\end{array}$ & $\begin{array}{l}\text { Mean } \\
\text { biomass } \\
\text { achieved at } \\
\text { the end }(\mathrm{g})\end{array}$ & $\begin{array}{l}\text { Net biomass } \\
\text { acquired } \\
\text { earthworm }{ }^{-1} \text { at } \\
\text { the end }(\mathrm{g})\end{array}$ & $\begin{array}{l}\text { growth rate } \\
\mathrm{mg}_{1} \text { worm }\end{array}$ \\
\hline Acclimated & $2.27 \pm 0.18^{a}$ & $3.58 \pm 0.3^{\mathrm{a}}$ & $3.44 \pm 0.24^{\mathrm{a}}$ & $1.31 \pm 0.12^{\mathrm{a}}$ & $21.83 \pm 0.01^{\mathrm{a}}$ \\
\hline Unacclimated & $2.17 \pm 0.11^{\mathrm{a}}$ & $2.45 \pm 0.1^{b}$ & $2.45 \pm 0.13^{b}$ & $0.28 \pm 0.02^{b}$ & $4.67 \pm 0.01^{b}$ \\
\hline
\end{tabular}

\section{- Polyphenols}

Changes in polyphenols concentration was reported in fig. 1, mixture with acclimated earthworms showed highest phenols concentration reduction (72\%), indicating that acclimatized earthworms have well tolerated their culture medium. Zenjari and Nejmeddine [6] attributed the decrease of phenol concentration to the microbial bioconversion of polyphenolic compounds and their interaction with secondary metabolites contributing to the biosynthesis of humic substances. While unacclimated earthworms did not allow for a significant reduction in the phenols concentration (41\%). These results demonstrate the positive effect of the acclimatization of earthworms towards OMWW in order to obtain a high rate of detoxification.

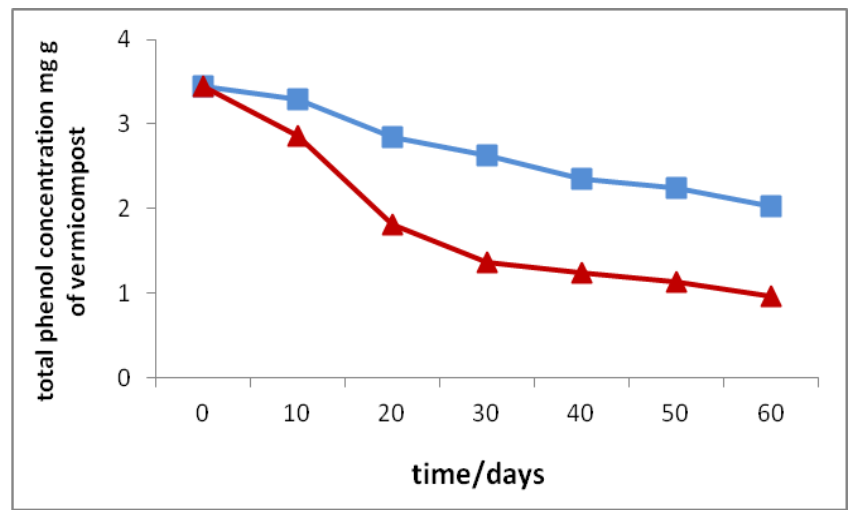

Figure 1: Changes in phenols' concentration in mixture with unacclimated $(--)$ and acclimated $(-\mathbf{-})$ earthworms during vermicomposting.

\section{Conclusion}

The results of this work confirm that acclimatization of Eisenia andrei allows a higher reproductive rate and a higher rate of OMWW detoxification than unacclimated earthworms. The rate of phenols reduction (72\%) obtained with acclimatized earthworms demonstrates the positive effect of acclimatization. Although OMWW are 
a recalcitrant organic by-product for decomposition, acclimatization of earthworms can enhance their potential adaptation to high OMWW concentrations.

\section{Acknowledgements}

This research work was financially supported by PHC Toubkal TBK/15/03 - Campus France N $32548 X \mathrm{XH}$ project.

\section{References}

Bouché MB. Lombriciens de France: écologie et systématique. Annales de Zoologie Ecologie Animale, INRA Editions, Paris, France 1972, pp. 671.

Edwards CA, Arancon NQ. The use of earthworms in the breakdown of organic wastes to produce vermicomposts and animal feed protein. Earthworm ecology, 2nd edn. St. Lucie Press, Boca Raton, FL 2004: 345-380.

Ganesh PS, Gajalakshmi S, Abbasi SA. Vermicomposting of the leaf litter of acacia (Acacia auriculiformis): Possible roles of reactor geometry, polyphenols, and lignin, Bioresource technology 2009; 100:1819-1827.

Garg V, Yadav Y, Sheoran A, Chand S, Kaushik P. Livestock excreta management through vermicomposting using an epigeic earthworm Eisenia foetida, The Environmentalist 2006; 26:269-276.

El Hajjouji H, Fakharedine N, Ait Baddi G, Winterton P, Bailly J, Revel J, Hafidi M. Treatment of olive mill wastewater by aerobic biodegradation: an analytical study using gel permeation chromatography, ultraviolet-visible and Fourier transform infrared spectroscopy, Bioresource technology 2007; 98: 3513-3520.

Lakhtar H, Roussos S. Solid State Fermentation of Lentinula edodes on Solid Olive Substrate: Evaluation of Growth Factors. Journal of Applied Sciences 2016; 16:562-569.

Melgar R, Benitez E, Nogales R. Bioconversion of wastes from olive oil industries by vermicomposting process using the epigeic earthworm Eisenia andrei. Journal of Environmental Science and Health, Part B 2009; 44: 488-495. 